\title{
Understanding the dynamics of the Seguro Popular de Salud policy implementation in Mexico from a complex adaptive systems perspective
}

\author{
Gustavo Nigenda ${ }^{1}$, Luz María González-Robledo ${ }^{1 *}$, Clara Juárez-Ramírez ${ }^{2}$ and Taghreed Adam³
}

\begin{abstract}
Background: In 2003, Mexico's Seguro Popular de Salud (SPS), was launched as an innovative financial mechanism implemented to channel new funds to provide health insurance to 50 million Mexicans and to reduce systemic financial inequities. The objective of this article is to understand the complexity and dynamics that contributed to the adaptation of the policy in the implementation stage, how these changes occurred, and why, from a complex and adaptive systems perspective.

Methods: A complex adaptive systems (CAS) framework was used to carry out a secondary analysis of data obtained from four SPS's implementation evaluations. We first identified key actors, their roles, incentives and power, and their responses to the policy and guidelines. We then developed a causal loop diagram to disentangle the feedback dynamics associated with the modifications of the policy implementation which we then analyzed using a CAS perspective.

Results: Implementation variations were identified in seven core design features during the first 10 years of implementation period, and in each case, the SPS's central coordination introduced modifications in response to the reactions of the different actors. We identified several CAS phenomena associated with these changes including phase transitions, network emergence, resistance to change, history dependence, and feedback loops.

Conclusions: Our findings generate valuable lessons to policy implementation processes, especially those involving a monetary component, where the emergence of coping mechanisms and other CAS phenomena inevitably lead to modifications of policies and their interpretation by those who implement them. These include the difficulty of implementing strategies that aim to pool funds through solidarity among beneficiaries where the rich support the poor when there are no incentives for the rich to do so. Also, how resistance to change and history dependence can pose significant challenges to implementing changes, where the local actors use their significant power to oppose or modify these changes.
\end{abstract}

Keywords: Complex adaptive systems, Universal health coverage, Stakeholder analysis, Causal loop diagram, Seguro Popular, Mexico

\footnotetext{
* Correspondence: luz.gonzalez@uaem.mx

${ }^{1}$ School of Medicine, Morelos State Autonomous University, Calle Leñeros

esquina Iztaccíhuatl s/n Col. Volcanes, Cuernavaca Morelos CP 62350, Mexico

Full list of author information is available at the end of the article
} 


\section{Background}

Health systems are complex adaptive systems characterized by the constant interaction and feedback between its constituting parts, leading to continuous changes and adaptation and often unexpected consequences [1, 2]. Complex adaptive systems frameworks have been increasingly used in recent years to understand the complex nature of introducing new policies and how they work and influence health systems [3-6], but applications of how this can be done in practice are still scarce, especially in low- and middle-income countries [5, 712]. This paper seeks to add to this body of knowledge and understanding by applying a complex adaptive systems (CAS) framework to the question of how do health systems actors respond to new policies, more specifically, how do they react to, adapt or change the path of policy implementation with respect to the way it was conceived. We used the implementation of the financial reform policy "Seguro Popular de Salud" (SPS) in Mexico as a case study to explore this question.

In 2003, Mexico's public health system experienced a historical change in its financial structure. After decades of chronic underfunding, the Health Social Protection System (HSPS), and its financial component Seguro Popular de Salud, was introduced to channel new funds to provide a broad package of health services to around 50 million Mexicans who were not affiliated to any of the traditional social security institution [13], founded to provide health and other social services to formal industrial workers. By 2012, SPS managed to generate an unprecedented flow of financial resources equivalent to the triple of resources that the Ministry of Health (SSA in Spanish) accounted for in 2000 [14]. As a financial policy within the public system, SP defined its objectives to (a) improve the distribution of public financial health resources across the Mexican states, (b) reduce the inequities between those covered by social security schemes and the rest of the population, and (c) reduce out-ofpocket and catastrophic expenditure. The first two were clearly accomplished over the rolling out period $[15,16]$, but the third has only been partially accomplished. Literature shows that the effect of SPS has concentrated on the reduction of catastrophic expenditure [17, 18].

In addition, SPS was also conceived to produce improvements in the performance of the public system including increasing the number of the affiliated population and the distribution of non-financial resources (personnel, medicines, equipment) among the affiliated populations throughout the country [19-22]. Empirical evidence demonstrated improvement in patient satisfaction due to drug availability, reduced waiting times and better treatment for ambulatory and hospital care [13, $23,24]$ and improved access to specific services such as screening for breast cancer, diagnosis and treatment of diabetes, and specific vaccines (e.g., measles) [13]. There are also indications of reduced inequities in access to health services, but the evidence is not yet conclusive. Important reduction in the use of private hospital services was also observed for new affiliated population under SPS [25-27].

Although SPS has been demonstrated to produce various relevant effects, not enough attention was given to the implementation process and its implications on the health systems and its overall goals. Therefore, while SPS has achieved several hard-to-reach objectives, it is still confronting enormous managerial challenges that could be hindering its ability to ensure that its ultimate goal is fulfilled-effective universal health coverage of all Mexicans, through equitable access to affordable and good quality health services with financial risk protection $[13,28]$. After more than 10 years of its inception, the policy implementation process has endured important variations across the 32 states [13], but we still do not clearly understand the reasons behind these variations and how they may have affected SP capacity to accomplish systemic managerial goals.

\section{Health systems as complex adaptive systems}

Health systems share the same characteristics of CAS [29]. Although CAS frameworks and methods have been widely used to explore and understand complexity in various disciplines such business, management, and education, its application in health is relatively recent [12, $30,31]$. In the past decade, several studies concerned with health systems interventions or strengthening indicated the importance of using a different perspective than the traditional linear approach that have been predominantly used in the health literature so far, but little guidance is available as to how to apply it [30, 32, 33]. The relevance of understanding and analyzing health systems problems using a CAS perspective stems from the following fundamental characteristics of CAS that also characterize health systems $[2,29,34]$. The interactions among their components are non-linear and constantly changing, their dynamics are unpredictable and sometimes counter-intuitive, and they are capable to self-organize, adapt, and learn from experience on a constant basis [35-37]. Therefore, this inherent interconnectedness and interdependence between health systems components, its actors, and the context in which they operate create a continuous process of feedback loops with unpredictable time lags between the cause and effects, collectively creating a "dynamic complexity" [38].

As described by Paina and Peters (2011), CAS framework provides a useful approach to analyze the behavior generated by complex systems and its actors to understand how the behavior was produced, what were the associated phenomena that occurred, and how they 
influenced the system and the implementation of policies [31]. Some of these CAS phenomena include network emergence, where new hubs emerge that use their collective power to influence the system in a way that is greater than the sum of their individual powers; path dependence, where states are not only influenced by the policy itself but also by the initial conditions in each of these states and decisions taken along the way; phase transitions where threshold effects occur creating a new status in the system "whether around the rapid adoption of a policy stalled for years, changes in social norms concerning health behaviors, or a new demand for health services", and feedback loops where an input to the system generate a reaction or an outcome that feedbacks into the system as an input to generate new processes or effects [31].

All these phenomena are very relevant to our research question. Understanding how Seguro Popular de Salud's policy implementation follows or differs from its operational guidelines will not only clarify how and why SPS's implementation took the routes it chose during these 10 years but also illuminate the thinking and design of future policies. What causes these changes? Why implementation guidelines are so difficult to implement as conceived? All these questions require an analytical approach that embraces complexity and the adaptive nature of complex systems such as the health system.

The objective of this study is, therefore, to apply a complex adaptive systems perspective to understand (1) the role of key actors and the way their responses and power shaped the policy through its implementation; (2) how the system adapted and modified the implementation of the policy and; (3) the dynamics by which this happened. The answers to these questions offer a critical insight to potential revisions or redesign of the policy and/or development of an alternative one.

\section{Methods}

We used a case study approach to analyze the implementation of a financing reform policy, the Seguro Popular de Salud in Mexico from a CAS perspective This approach was selected for the following reasons: (1) the case study permits to analyze in depth a contemporary phenomenon in its real context, especially when the limits between the phenomenon and its context are not evident; (2) it focuses on responding the "hows" and the "whys" of a scarcely studied phenomenon; (3) relevant lessons could be obtained from a complex situation, based on the overall understanding of such situation, and (4) the results of the study can contribute to yield proposals for the definition or redefinition of public policies and give way to new research proposals $[39,40]$.

\section{Data sources}

A combination of secondary data sources were used to inform our analysis, the majority of which were from four consecutive evaluations of Seguro Popular de Salud's implementation processes carried out between 2007 and 2012 and published elsewhere [19, 39-43]. The four evaluations interviewed a total of 515 decisionmakers at the federal and states levels, 1031 doctors and nurses from primary care units, and 2485 beneficiaries, using structured and semi-structured interviews. These reports also contain data on the number of enrolled beneficiaries, management of financial resources, and the structural and legal status of the financial intermediary unit in the different states as well as key informant interviews with managerial and technical staff at national and state level around various implementation processes and associated challenges [22-24]. Three of the authors (GN, LMGR, and CJ) participated from the start in the planning and conduction of the four evaluations as well as in the field data collection. However, in each evaluation a team of 15 researchers were involved along the process. The evaluations were financed by the Federal Secretariat of Health and were carried out by the National Institute of Public Health of Mexico (NIPH).

Other sources of information include financial flows obtained from the National Commission; the SP conceptual, financial, and operational guidelines; and laws, guidelines, and other normative documents that support the SP operations including the 2007-2012 SP "White Book" [44].

\section{Applying a complex adaptive systems framework}

Peters DH (2014) provided a comprehensive review of the relevant methods to address problems of complexity within health systems [12]. The methodological paper by Paina and Peters (2011) provide a detailed framework for how to explore and analyze complex interventions as they are scaled up using a complex adaptive systems perspective [31]. They provide descriptions of the different phenomena that may occur when systems change as a reaction to intervening as described above, with examples of how they can be explored and tested, which we applied in this study. More specifically, data from the four SPS evaluations were reanalysed to explicitly explore what changes occurred in the policy over the first decade if its implementation, how the change was triggered, by whom action was taken, and how this affected the policy and its intended goals. Whenever a CAS phenomena or an action (by the system or its actor) was detected, additional secondary data sources were sought to further explore or confirm the observation. This iterative process was visually depicted using a causal loop diagram as explained below to specifically look at relationships between triggers, actions, and change in the form 
of feedback loops. Causal loops are very good means to go through such process as was successfully used by Rwashana et al. 2014 [4], Varghese et al. 2014 [11], and Paina et al. 2014 [5].

\section{Analysis of data}

First, a detailed analysis of the main actors, their incentives, role, power, and responses to the implementation of the policy, including the way each of them adapted or interpreted the policy at its different phases of development, was performed. Then, the various changes and adaptations in the policy's implementation and the reasons and dynamics involved in these adaptations were extracted from the various data sources taking into account different variations to policy adaptations in various states or by various actors. Next, the study team, which constitutes multi-disciplinary Mexican and international researchers, used this information to interpret the changes in the implementation of the policy and the mechanisms by which they happened. This iterative process was guided by the development of a causal loop diagram depicting the original and modified operational framework and the feedback loops that evoked those changes. This stage of the analysis was instrumental for the next and final stage, which employed a CAS framework to explore the mechanisms by which the changes occurred and the associated CAS phenomena (see below).

\section{Causal loop diagram}

The generated list of changes in the implementation of SPS and its link to the various actors (see Table 1) were used to develop a causal loop diagram to understand how the implementation of policy was carried out over time and what were the dynamics involved in this process. Causal loop diagrams provide a useful approach to illustrate complex systems characteristics such as dynamic relationships, non-linearity (e.g., in the form of delays in outcomes after an initial intervention or action), and feedback loops. They offer a means to understand, interpret, and discuss dynamic relationships using a common terminology and techniques [45]. Variables are usually labeled in neutral terms using positive and negative signs on the arrows that link variables to show the direction of influence of one variable on another. Feedback loops occur when arrows connect a variable to itself through one or a series of variables.

There are two types of feedback loops. Balancing loops, also called neutralizing loops, can be seen when a resulting outcome was intending to neutralize an action or a policy to bring the system back to the desired state. Reinforcing loops depict a vicious circle that occurs when an action creates an exponential outcome that keeps increasing overtime, being reinforced by the variable that caused it, until a break in the cycle happens. Reinforcing loops can be positive (desired) or negative (undesired). A reinforcing loop has the same signs in all the variables involved in this loop while a balancing loop have opposite signs, since the intention is to reduce the effect of a certain variable to bring the system back to another (or the initial) desired state. A delay in the outcome is denoted by $\mathrm{A} \longrightarrow \mathrm{B}$.

\section{Ethical considerations}

Ethical approval for the four evaluations was obtained from the National Institute of Public Health's Ethics and Research Commission. Key informants were told prior to the interviews about the objectives of the interview and the evaluation. Consent letters were signed by all those who accepted to be interviewed. All information provided by informants was safely stored in a computer where only the general coordinator of the evaluation had access to.

\section{Results}

In this section, we first describe the range of the main actors that were involved in the implementation of the policy, the characteristics of their interactions, and how they coped and adapted in reaction to the policy (Table 1). We then focus on how their responses led to modifications of the policy implementation over time followed by a description of the CAS phenomena that emerged from the analysis (Fig. 1).

\section{The range of actors and their responses to the policy}

Table 1 describes the range of main actors involved in the operation of SPS by 2012, their incentives, role, power, and response to the policy implementation. The new role of main actors and how they emerged are described in turn below.

All actors identified are public and private actors that normally interact in the managerial processes that are carried out at federal and state levels. However, within SPS's original design, some were not included, others were included and maintained their original role while a third group were included but modified their role.

The state's treasuries were not explicitly mentioned in the original regulatory framework but they were the recipients of federal funds coming from the National Commission in order to register them to be subjected to federal audits. The assumption was that it would guarantee the transparent use of funds and facilitate accountability. In practice, the transfer of funds from treasuries to REPSS was seriously delayed (taking weeks and even months to be completed) which resulted in a new regulatory requirement for compulsory reports about delays [46]. Other federal health subsidies were by the State Secretariat of Health in a single pot to facilitate the 
Table 1 Main actors, original and modified roles, and influence in the allocation and management of Seguro Popular financial resources

Actor

National Commission of the Health

Social Protection Policy (considered

in the guidelines and had the same

role as originally intended)

State government treasury (not explicitly mentioned in the origina guidelines but having a role) the flow of funds

State Ministry of Health (considered Provide health services through in the guidelines but its role changed) its public network

transfer them to the states
Provide a mechanism for auditing Receive funds from the National

Role in the system

ective/ilncentives desired goals

Stewardship

To evaluate the REPSS performance

as well as the overall system.

To support the accountab

funds

Receive funds from the National the state's financial system to capitation
Receive funds and allocate according

Power

High but without legal capacity

of sanctioning

It can delay disbursement of unds, e.g., if financial reports are

not received

It cannot act if they detect

mishandling of resources

Policy responses

source

-Adapted and modified the policy

-Changed the definition of capitation

from family to individual

-Accepted the state's $15 \%$ financial

share to be represented by previous

investments

-Introduced a cap on spending on medicines (30\%) and hiring (40\%)

-Families belonging to III and IV

deciles were exempted from pre-

payment

High because of legal capacity to -Kept funds as much as they can to handle finances and sanctioning obtain bank interests

-Kept REPSS inside its structure to keep hold of federal financia

High, e.g., in terms of fund allocation according to their priorities and network since it substituted the original role of REPSS

resources

-Did not implement capitation but maintained historical budget due to lack of information and managerial. capacity

- Initially issued short staff contracts to reduce costs but under pressure had to extend contracts

-Limited private sector purchasing of services

Original: Purchasing of services

State Health Social Protection Regime (REPSS) (considered in the guidelines but changed its role)

from public and private in an equitable and efficient way Revised (except in one state): ensure the highest number of affiliates registered and reported to bring more funds to the state

Original: financial intermediary

Affiliate new users

Protect users' rights

Management of financial resources

Purchasing of services,

Accountable to state and federal

authorities

Revised (except in one state):

Administering the funds from

affiliating new people into the plan.

Transfer this information to the

National Commission

To participate in the allocation of

resources to public health units

National Workers Union (not considered in the guidelines but acquired an active role)
Represent the interests of unionized workers towards the employer
Negotiate the regularization of

contracts.

Monitor the process of regularization ow power or influence in allocation of funds

Their role shrunk over time by

being absorbed by the state

$\mathrm{MOH}$

- Increased number of affiliated

families, e.g., by re-interpreting the

guidelines to identify single membe

families, to increase the funds

allocated to the state
$\mathrm{MOH}$ they became increasingly

passive

High: Every regularized worker pays a $2 \%$ fee of the value of

-Became active in the regularization contract to receive protection with top federal players 
Table 1 Main actors, original and modified roles, and influence in the allocation and management of Seguro Popular financial resources (Continued)

Contracted workers

having active role)

Pharmaceutical retailers (Not considered in the guidelines but

Participate in bids and sell their products

\section{Obtain cor}

having an active role)

Pharmaceutical distributors (NEW)

Win the bid for distributing drugs Negotiate to win the bid (not considered in the guidelines but within the state

acquired an active role)

State health bureaucracy (considered As possible:

in the guidelines and had an active

role)

-Use funds to cover its needs

-Continue to function as before

Health units (providers) (considered

in the guidelines but had a passive

role)

Beneficiaries affiliated to Seguro Popular (considered in the guidelines and acquired an active role)

High —in terms of flexibility to

as they have to deal with limited

number of providers (mostly

public sector) on medicine pricing levels

Became active in the regularization of contracts process by accepting new contracts negotiated by the union

High: there are limited number of -Depending on the state, retailers retailers and they lobby to agree negotiated highly profitable contracts

- Used their corporative and

marketizing capacity to sell their products and to agree on drug prices used in bids

Low-as there is more competition - Used different marketing strategies to win distribution bids and to convince the states that they could reduce allocation times despite the cost involved.

As initially no sanction system existed (before auditing started in 2009), some:

1. Bought medicines at high prices 2. Bought non-authorized goods 3. Contracted health workers without demonstrated competence

Receive resources and provide services to the affiliated population

No power as they do not receive any funds directly

o incentive to change status quo-business as usual

-Complained about not being heard or participate actively in the allocation process or decision-e.g., responding to the health challenges they face

Low but increasing-e.g., if they organize themselves to exert more pressure

-As they received information about their rights, they increasingly became more vocal in obtaining better services and medicines 


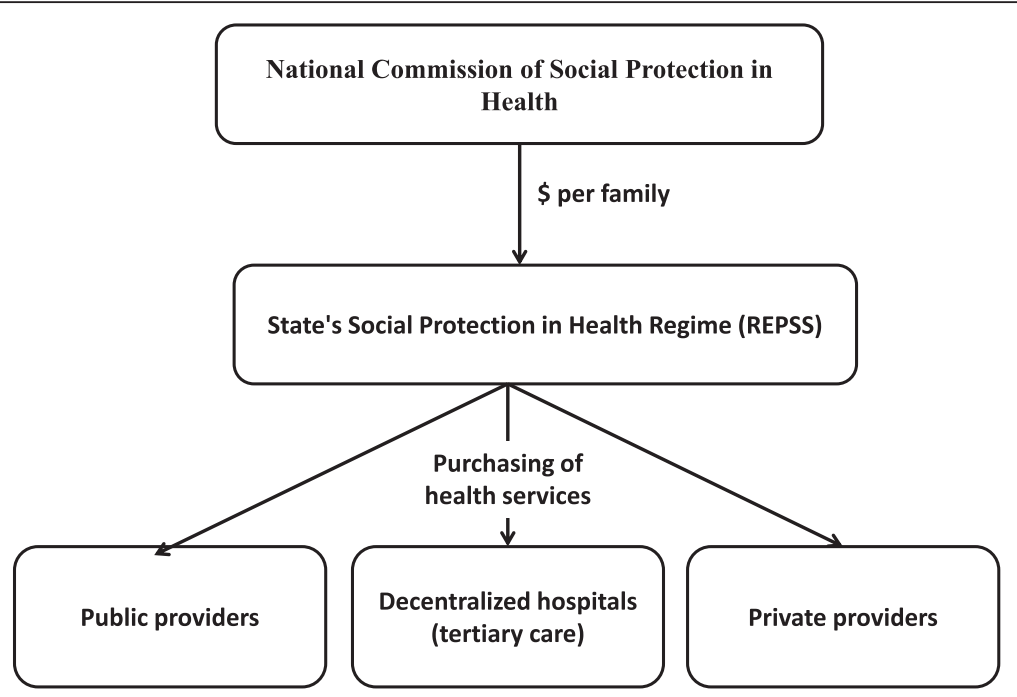

Fig. 1 Initial design of Seguro Popular policy

distribution across the different programs that in some states created a great administrative confusion. REPSS in most states was located within the SSA's structure and became subjected to the SSA decisions on how to pool and when to distribute the funds.

The participation of national workers union was not considered in the original design. It formally represents the interests of the SSA permanent workers but not of temporary employees. The union became agile to participate in negotiations to provide better labor conditions for the new short-term non-permanent employees that escalated after the introduction of SP $[42,47]$. The negotiations resulted in setting a minimum period for short-term contracts of 12 months, with benefits included, and it provided the union with a $2 \%$ salary contribution for each new contract as a union fee [42, 47]. These new conditions are known as the "regularization of contracts."

The other important actor showing an emerging role is the pharmaceutical wholesale retailers. These enterprises, enjoying a limited market competition, also put pressure on the states SSA middle-range managers to influence purchasing decisions. Although the medicines purchasing process is carried out through public bidding, enterprises initially managed to negotiate excessively high prices in some states or provided cheaper alternatives to the products included in their bids after the signing of the contracts [28]. A number of pharmaceutical distributors identified a market niche in the transportation of medicines from SSA central premises to health care units, particularly those located in remote areas.

Finally, an actor that is diffused into the institutional structure is the SSA middle-range bureaucracy, which involves the various administrative levels all the way from the state secretariat to the front-line health providers. Being responsible for various expenditure decisions across the implementation process, several heterogeneous behavior and un-authorized expenses were reported such as purchasing of non-authorized vehicles and equipment, accepting bids for medicines well beyond the unitary prices defined by the federal government authorities, and contracting health workers that do not fulfil the minimum required skills or qualifications that receive salaries well above the norms [43]. While these practices have been detected by the federal audit system, the original SPS design did not foresee a penalty or sanction system that can allow the National Commission, responsible for tracking the use of funds, to address these practices in a legal way so while they could point it out to the respective administration, they had no power to enforce a change.

\section{Adaptations in the course of the policy implementation}

Figure 2 is a causal loop diagram that illustrates seven modifications or adaptations of the policy implementation (highlighted in circles) and the associated balancing and reinforcing feedback loops that evoked the changes. The figure should be read from the center outwards. In the center of the figure is the National Commission. The rectangles show the five main components of the policy identified and how each of them has been modified during the course of the implementation resulting in seven modifications (including six feedback loops) representing either the system's or the actors' response to the original design and how they coped with it or adapted it. Feedback loops were generated during the 10 years of implementation contributing to its modifications and adjustments, each one of them of a different nature. We discuss the seven modifications and the associated feedback loops in turn below, referring to the circles in Fig. 2 starting in a clockwise manner from the bottom. 


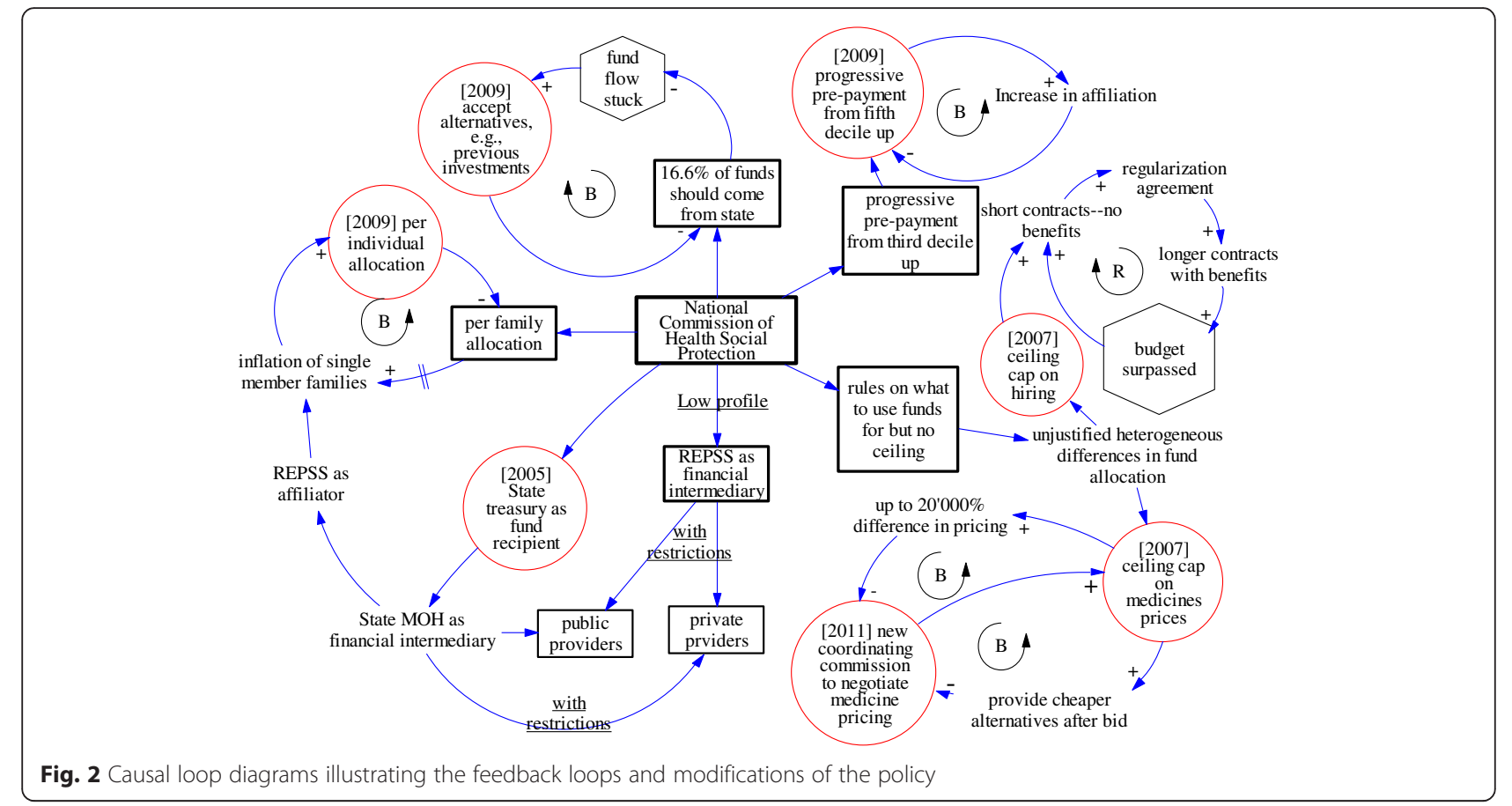

Establishment of the State Secretariat of Health as de facto financial intermediary, rather than REPSS. Given that most REPSS were housed in the state's SSA, the latter influenced all REPSS decisions and became the de facto financial allocator therefore halting the original intention to separate purchasing from provision of services $[41,42]$. Not surprisingly, preference was given to allocate funds in public units and purchasing services from private providers was limited. In addition, historical budgeting rather than per capita budgeting remained the main criteria for allocation of funds to health units. This was attributed to a lack of managerial capacity within the state to switch to per capita budgeting and planning, limited information, and perceived complexity of setting up a whole new system to identify where population resided and what services are they effectively demanding and consuming.

From family allocation to per capita allocation of funds. In the original design, the capitation estimate was based on an average family size of 3.8 members. Funds started flowing based on these criteria in the initial years, but by 2007, the National Commission noted that the number of one-person families had grown unexpectedly in several states. According to the original guidelines, it was possible for above 18 individuals to be considered a new family unit even if they still reside with their parents which created an incentive to do so to increase the funds allocated to the various states. In response, the National Commission revised the operational guidelines in 2009 to base the per capita allocation of funds per capita and not per family unit. This revision benefited the Southern states, where poor families tend to be bigger in size [43].

Changes in what the states' financial contribution to SP's fund is interpreted. Each state was expected to provide proof of the availability of their state contribution up-front before receiving the remaining portion from the federal level. Several states struggled to demonstrate ear-marking these funds upfront, arguing that they were part of their ongoing investments to support the various health services for their population and therefore historic investments that have been incurred should be considered as part of their contribution. This dispute threatened the flow of funds to the states, which would hamper the impact of the policy as a whole. With more states supporting the arguments, the National Commission decided to develop new guidelines in 2009 that formalized this practice, therefore, guaranteeing the flow of federal resources through the system [43].

Changes in pre-payment regulations. The fourth source of funds for Seguro Popular de Salud is the pre-payment made by households belonging to the third income decile or higher. However, it became extremely difficult to collect pre-payment fees from households. Over the existence of SP around 92-95\% of the enrolled families did not pay fees [48]. After refining the instrument for identification of socio-economic status for the rest of income deciles and failing to increase fee collection, the National Commission opted to exempt the third and fourth income deciles from paying the fee, which was also formalized in 2009. The objectives of this change were mainly two: to be able to speed up the process of 
enrolment in order to attain the $100 \%$ affiliation goal by 2012, the last year of the federal administration, and to reduce the costs of collecting the fee from those groups of populations that presented more difficulties to do so.

Introducing a ceiling for expenditures on human resources. Contracting of new health workers was the major source of expenditure in SP. In the early years, the National Commission noted that some states spent up to $70 \%$ of the funds in contracting. In response, they negotiated a ceiling with the states for a maximum of $40 \%$ of the total funds to be spent on this budget line. However, by 2010, after the change in contracting modality, 23 states were surpassing the $40 \%$ ceiling which explains why this component still represents a major challenge [28, 41, 43].

Introducing a ceiling for expenditures on medicines. The second biggest source of expenditures has been purchasing and procurement of medicines. Similar to contracting, the National Commission negotiated with the states on establishing a ceiling of $30 \%$ of total funds for the purchasing of medicines [28, 41, 43].

Establishment of a new Coordinating Commission for the Negotiation of Prices of Medicines and other Inputs. While medicines' expenditures seemed to be contained within the $30 \%$ ceiling, various coping strategies have emerged from pharmaceutical retailers in response to the cap. For example, by negotiating different unit prices for some medicines in different states and/or providing cheaper alternatives after the bid was accepted [18]. The National Commission, having noted this increasingly heterogeneous and irregular use of funds, convened key federal stakeholders and regulators together to establish new guidelines for the purchasing of medicines at national level. This involved the creation of a new Coordinating Commission for Negotiating the Price of Medicines and other Health Inputs that was responsible to negotiate, as a single public entity, unitary prices of medicines with individual drug manufacturers [49].

\section{Complex adaptive systems phenomena emerging from this analysis}

In this section, we describe the various complex adaptive systems (CAS) phenomena that we identified through our analysis. They include phase transitions, unexpected consequences, resistance to change, history dependence, coping mechanisms, emergence of networks, delays and non-linear outcomes, and feedback loops.

Regarding phase transitions, the design of Seguro Popular represented a major transformation in the operational rationale of Mexico's public health sub-system including innovations in financing, allocation of resources, definition of explicit packages of services, management procedures, and role and rights of users as newly "insured" populations. However, our analysis shows that the transition is partial and has mainly occurred in some of the components, particularly the financial component of the original design, expecting changes in other components to happen in further stages.

There are several examples of unexpected consequences that emerged from our analysis. One of them is the rise of the number of affiliated families, which was the basis for fund allocation to the states, due to the unexpected increase of one-person families. This example offers an interesting observation of how policies may be interpreted by its implementers when the details are not clearly defined or provide room for various interpretations. As the guidelines opened the possibility for the states to consider individuals above 18 , who are not students, to be regarded a new family unit, probably assuming they may be in the workforce, several states interpreted this as a blank provision and therefore inflated the number of one-person families to increase the resource flows allocated to them.

Resistance to change typically appear in reaction to new policies and our analysis of Seguro Popular de Salud provides some examples. The first is the resistance of the state's SSA to guarantee their share of resources to SPS as liquid funds before federal funds are disbursed. Another example is how households found ways to avoid paying the pre-payment conditional on income level. A third example is the strong preference of local health managers to maintain historical budgeting as the basis for allocating funds, rather than per capita based on new affiliates. This same example is also an illustration of history dependence where the past dictates the future and changing the ways of working and spending is not always easy or fast to implement.

Delays and non-linearity were reflected in the way various outcomes, and changes were observed in the various states. For example, the speed by which states started inflating the number of families and their strategies to negotiate the allocation of their $16.6 \%$ coresponsibility as liquid funds up-front before the remaining of the fund is disbursed to them. The main non-linearity example is that the availability of resources (e.g., medicines, workers) and the capacity to produce services, particularly at the first level of care, does not correspond with the investment that Seguro Popular de Salud has made into the system. As to coping mechanisms, a good example is the alternatives pharmaceutical retailers' sought in response to the imposed cap on expenditures on medicines as explained above.

Feedback loops occurred in various ways as described above and illustrated in the CLD in Fig. 2. Finally, various examples of emergence of networks and their collective impact were identified. For example, in the way how pharmaceutical distributors emerged and coalesced to develop a structured way of interacting with the 
implementers of the policy; how service providers collectively formed strong negotiation mechanisms to ensure that the status quo of historical funding prevails [23, 24]; and how the states gradually managed to exert pressure on the National Commission leading to their reformulation of the state's contribution and what it entails.

\section{Discussion}

One of the main strengths of this study is that it sought to apply a complexity lens through a CAS framework to understand the complex nature of implementing Seguro Popular de Salud in Mexico. While previous studies focused on top level parameters and indicators such as the increased volume and flow of funds to the health sector $[13,17,18,50]$, this study's main interest is how did this happen and what modifications and coping mechanisms were involved, from the perspective of complex and adaptive systems. A limitation, however, is that it heavily relies on secondary data sources corresponding to a specific period of time (2007-2012). Thus, the current situation of SPS implementation could have changed from the one that was originally described.

The lessons of this analysis are applicable to any other settings aiming to incorporate a flow of fresh funds to improve the system's performance and capacity. Our study emphasizes that no matter how evidence-based or logical the aim and design of a policy is, its implementation will undoubtedly follow different paths that are mostly unpredictable and unanticipated [51, 52]. Strategic governance of the systems and continuous evaluation and refining of policies are, therefore, essential for the execution of policies as it requires adequate knowledge of the complex behavior of health systems and substantial capacity of negotiation and leadership to be able to detect and adjust to the change in behavior of the system and its actors striving for maintaining the desired outcomes and goals and mitigating undesired consequences [53].

For example, resistance to change was also shown in other contexts has been associated with the implementation of new policies including financial reforms. In Tanzania, a financial reform that was aimed at expanding the health insurance coverage to the whole population failed to expand beyond $10 \%$ of the population after 10 years of its implementation due to resistance from district level implementers who felt not involved in the design of the policy and that it was imposed on them from the central level [54]. History dependence in our case illustrated by the strong push by the local health managers to maintain historical budget level as the basis for allocating funds was also observed in other settings, e.g., in the Chinese reform,, emphasizing that changing the ways of working and spending is not always easy or fast to implement [55].
Two specific lessons for future financial reforms also emerged from our study. First, while Mexico attempted to avoid the risk of channelling the new financial flows through the private sector as in the case of Colombia in its 1990s reform, which created an enormous concentration of financial resources and corruption practices in these units [56], maintaining these new financial flows in the public sector exposed them to the power and incentives of the state governments which also have has a different set of risks and challenges as described in this paper. A second lesson is the difficulty of implementing a solidarity approach where the rich support the poor in collecting fees insurance premiums. In SPS, beneficiaries, including the rich, systematically avoided paying these fees, presumably because they did not see the benefits to them of doing so. The same experience was encountered in the Chinese reform [57].

In summary, applying a CAS framework to this analysis expanded our capacity to describe and understand this complex policy in a much more insightful and realistic ways, providing much richer and meaningful interpretation of the effects of the policy and a better understanding of how and why it was adapted in the course of its implementation. Policies that involve a monetary component share similar "risks" for perverse behaviors and this study carry lessons for relevant policies in other settings.

\section{Conclusions}

Applying a systems thinking approach to future policy design, implementation, and evaluation, recognizing the characteristics of complex adaptive systems and embracing approaches that are consistent with this complexity would offer valuable steps forwards in the way policies are conceptualized, designed, and implemented. This process would involve the wider range of key stakeholders in the policy design stage, analyzing the incentives, roles and power of the key actors, including those that may emerge during the implementation of the policy, considering middle-range and front-line implementers as well as the beneficiaries, and brainstorming on the possible unexpected consequences with these various key actors to try and mitigate some of them [29].

\section{Abbreviations \\ CAS: complex adaptive systems; CJR: Clara Juárez-Ramírez; CLD: causal loop diagrams; GN: Gustavo Nigenda; IDRC: International Development Research Centre; LMGR: Luz María González-Robledo; NIPH: National Institute of Public Health of Mexico; PRI: Partido Revolucionario Institucional; REPSS: State's Social Health Protection Regime; SP: Mexico's Seguro Popular; SSA: Ministry of Health; SSOH: State's Secretariats of Health; TA: Taghreed Adam.}

Competing interests

The authors declare that they have no competing interests. 


\section{Authors' contributions}

GN participated in the development of the conceptual framework, study design, and analysis, wrote the first version of the article, and participated in the drafting of subsequent versions. LMGR participated in the development of the conceptual framework, study design, and analysis and commented and incorporated data into different versions of the article. CJR participated in the analysis and commented and incorporated data into different versions of the article. TA participated in the development of the conceptual framework, study design and analysis, and in the drafting of the various versions of the article.

\section{Acknowledgements}

We would like to express our gratitude to the following institutions and people who supported this study at different stages of the data collection and analysis during the multi-year evaluation. The General Directorate of Performance Evaluation of the Ministry of Health of Mexico for providing the means to carry out the evaluations and for authorizing the use of data for the drafting of the paper, the National Coordination of Seguro Popular for providing information and accepting interviews with the research team, the Secretariat of Health, and REPSS in the states that in different moments were visited always showing availability to provide data and opinions about Seguro Popular de Salud. International Development Research Centre-Ottawa Canada (IDRC) hosted the main author over a year to reflect on the application of CAS into health systems. Special thanks to Sharmila Mhatre fro IDRC for her incredible support and to David Evans, Tessa Tan-Torres Edejer, and Joe Kutzin from World Health Organization (WHO) who provided insightful comments to the early versions of the document. The authors declare that the views expressed in this article are those of the authors and not necessarily those of the organizations they represent.

This study used data generated through the multi-year evaluation of Seguro Popular between undertaken by the National Institute of Public (NIPH) Health of Mexico through funding from the Federal Ministry of Health in Mexico. The publication of this article is funded by the Alliance for Health Policy and Systems research-WHO, as part of activities to advance the applications of systems thinking and was carried out with the aid of a grant from IDRC.

\section{Author details}

${ }^{1}$ School of Medicine, Morelos State Autonomous University, Calle Leñeros esquina Iztaccíhuatl s/n Col. Volcanes, Cuernavaca Morelos CP 62350, Mexico. ${ }^{2}$ Center for Health Systems Research, National Institute of Public Health, Av. Universidad 655, Santa María A, Cuernavaca CP 62100, Mexico. ${ }^{3}$ Health Systems and Innovation, World Health Organization, 20 Avenue Appia, Geneva, Switzerland.

\section{Received: 22 September 2015 Accepted: 7 May 2016}

\section{Published online: 13 May 2016}

\section{References}

1. Plsek PE, Wilson T. Complexity science-complexity, leadership, and management in healthcare organisations. Br Med J. 2001;323:746-9.

2. Plsek PE, Greenhalgh T. Complexity science: the challenge of complexity in health care. BMJ. 2001;323:625-8.

3. Gilson L, Elloker S, Olckers P, Lehmann U. Advancing the application of systems thinking in health: South African examples of a leadership of sensemaking for primary health care. Health Res Policy Syst. 2014;12:30.

4. Rwashana Semwanga A, Nakubulwa S, Nakakeeto-Kijjambu M, Adam T. Advancing the application of systems thinking in health: understanding the dynamics of neonatal mortality in Uganda. Health Res Policy Syst. 2014;12:36.

5. Paina L, Bennett S, Ssengooba F, Peters DH. Advancing the application of systems thinking in health: exploring dual practice and its management in Kampala, Uganda. Health Res Policy Syst. 2014;12:41.

6. Malik AU, Willis CD, Hamid S, Ulikpan A, Hill PS. Advancing the application of systems thinking in health: advice seeking behaviour among Primary Health Care physicians in Pakistan. Health Res Policy Syst. 2014;12:43.

7. Wilson T, Holt T. Complexity science-complexity and clinical care. Br Med J. 2001;323:685-8.

8. Rogers $H$, Maher L, Plsek PE. New design rules for driving innovation in access to secondary care in the NHS. BMJ. 2008;337:a2321. doi:10.1136/bmj. a2321.

9. Adam T. Advancing applications of systems thinking in health. Health Policy Res Syst. 2014;12:50.
10. Agyepong IA, Aryeetey GC, Nonvignon J, Asenso-Boadi F, Dzikunu H, Antwi

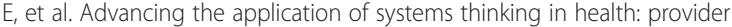
payment and service supply incentives in the Ghana National Health Insurance Scheme: a systems approach. Health Res Policy Syst. 2014;12:35.

11. Varghese J, Kutty VR, Paina L, Adam T. Advancing the application of systems thinking in health: understanding the growing complexity governing immunization services in Kerala, India. Health Res Policy Syst. 2014;12:47.

12. Peters $\mathrm{DH}$. Advancing the application of systems thinking in health: why use systems thinking? Health Res Policy Syst. 2014;12:51.

13. Knaul FM, González-Pier E, Gómez-Dantés O, García-Junco D, ArreolaOrnelas $\mathrm{H}$, Barraza-Llorens $\mathrm{M}$, et al. The quest for universal health coverage: achieving social protection for all in Mexico. Lancet. 2012;380:1259-79.

14. Cámara de Diputados LXII Legislatura. Recursos Asignados al Ramo 12 de Salud en el Presupuesto de Egresos de la Federación 2014. México: Nota Informativa notacefp/002/2014; 2014. Available online: http://www.cefp. gob.mx/publicaciones/nota/2014/enero/notacefp0022014.pdf.

15. Gómez-Dantés O, Sesma S, Becerril VM, Knaul FM, Arreola H, Frenk J. The health system of Mexico. Salud Publica Mex. 2011;53:S220-32.

16. Secretaría de Salud. Sistema de Protección Social en Salud, Evaluación Financiera. Secretaría de Salud. México, D.F: Primera edición/octubre; 2006. ISBN 970-721-382-5. Available online http://www.salud.gob.mx/unidades/ evaluacion/seguropopular/spss-tomoll.pdf.

17. Galarraga O, Sosa-Rubí S, Salinas-Rodríquez A, Sesma-Vázquez S. Health insurance for the poor: impact on catastrophic and out-of-pocket health expenditures in Mexico. Eur J Health Econ. 2009;11:437-47.

18. Knaul FM, Arreola-Ornelas H, Méndez-Carniado O, Bryson-Cahn C, Barofsky J, Maguire $\mathrm{R}$, et al. Evidence is good for your health system: policy reform to remedy catastrophic and impoverishing health spending in Mexico. Salud Publica Mex. 2007;49:S70-87.

19. Instituto Nacional de Salud Pública (INSP). Sistema de Protección Social en Salud. Evaluación de Procesos Administrativos 2007. Cuernavaca: Instituto Nacional de Salud Pública; 2008.

20. Santacruz-Varela J. Health insurance in Mexico and its trends. From the myth to the target. Rev CONAMED. 2010;15:195-203.

21. Gakidou E, Lozano R, González-Pier E, Abbott-Klafter J, Barofsky JT, Bryson-Cahn C, et al. Health system reform in Mexico 5-assessing the effect of the 200106 Mexican health reform: an interim report card. Lancet. 2006;368:1920-35.

22. Bonilla Chacín ME, Aguilera N. The Mexican social protection system in health. Universal Health Coverage Studies Series (UNICO) No. 1. The World Bank, Washington: 2013 Available online: http://siteresources.worldbank.org/ HEALTHNUTRITIONANDPOPULATION/Images/MexicanSocialProtection SysteminHealth.pdf.

23. Instituto Nacional de Salud Pública (INSP). Evaluación de Efectos del Sistema de Protección Social en Salud 2008. México: Instituto Nacional de Ciencias Médicas y Nutrición Salvador Zubirán; 2010.

24. Garrido-Latorre F, Hernández-Llamas H, Gómez-Dantés O. Dispensing prescriptions to persons affiliated with popular health insurance in Mexico. Salud Publica Mex. 2008;50:S429-36.

25. Cárdenas-Denham S, Ramírez de la Cruz E, Lozano Moheno I, Sánchez D. Levantamiento del panel de la encuesta nacional de afiliados al Seguro Popular. Centro de Investigación y Docencia Económicas (CIDE); México, 2012:59.

26. Grogger J, Arnold T, Leon A, Ome A. Efectos del Seguro Popular sobre el gasto en salud, utilización de servicio médicos y nivel de salud y resultados a largo plazo del experimento del Seguro Popular en México y evidencia de la Encuesta Nacional de Ingresos y Gastos de los Hogares (ENIGH). Centro de Investigación y Docencia Económicas AC (CIDE). México 2011: 28.

27. Consejo Nacional de Evaluación de la Política de Desarrollo Socia. Indicadores de acceso y uso efectivo de los servicios de salud de afiliados al seguro popular. México DF: CONEVAL; 2014

28. Nigenda G, Wirtz VJ, González-Robledo LM, Reich MR. Evaluating the implementation of Mexico's health reform: the case of Seguro Popular. Health Systems and Reform. 2015;1(3):217-228. doi:10.1080/23288604.2015. 103.1336.

29. De Savigny D, Adam T. (Eds). Systems Thinking for health systems strengthening. Alliance for health policy and systems research. World Health Organization (WHO). Geneva, Switzerland, 2009. Available online: http:// apps.who.int/iris/bitstream/10665/44204/1/9789241563895_eng.pdf.

30. Adam T, Hsu J, de Savigny D, Lavis JN, Rottingen JA, Bennett S. Evaluating health systems strengthening interventions in low-income and middleincome countries: are we asking the right questions? Health Policy Plan. 2012;27:9-19. 
31. Paina L, Peters D: Understanding pathways for scaling up health services through the lens of complex adaptive systems. Health Policy Plan 2011, doi: 10.1093/heapol/czr054: -1 .

32. Adam T, de Savigny D. Systems thinking for strengthening health systems in LMICs: need for a paradigm shift. Health Policy Plan. 2012;27:1-3.

33. El-Jardali F, Adam T, Ataya N, Jamal D, Jaafar M. Constraints to applying systems thinking concepts in health systems: A regional perspective from surveying stakeholders in Eastern Mediterranean countries. Int J Health Policy Manag 2014; 3: 399-407. doi:10.15171/ijhpm.2014.124.

34. Shiell A, Hawe P, Gold L. Complex interventions or complex systems? Implications for health economic evaluation. BMJ. 2008;336:1281-3.

35. Best A, Clark PI, Leischow SJ, Trochim WM. Greater than the sum: systems thinking in tobacco control. Bethesda: National Cancer Institute, US Department of Health and Human Services, National Institutes of Health; 2007.

36. Leischow SJ, Best A, Trochim WM, Clark PI, Gallagher RS, Marcus SE, et al, Systems thinking to improve the public's health. Am J Prev Med. 2008;35: S196-203.

37. Trochim WM, Cabrera DA, Milstein B, Gallagher RS, Leischow SJ. Practical challenges of systems thinking and modeling in public health. Am J Public Health. 2006;96:538-46.

38. Atun R. Health systems, systems thinking and innovation. Health Policy Plan. 2012;27:iv4-8.

39. Stake R: The art of case study research. Thousand Oaks, CA: Sage 1995:49-68.

40. Yin R. Case study research: design and methods. In: Applied social science research methods, 4th edition. Thousand Oaks: Sage Publications; 2009.

41. Instituto Nacional de Salud Pública (INSP). Evaluación Externa del Sistema de Protección Social en Salud 2011. Informe Final. 2011. Cuernavaca: Instituto Nacional de Salud Pública; 2011.

42. Instituto Nacional de Salud Pública (INSP). Evaluación del Sistema de Protección Social en Salud 2009. Cuernavaca: Instituto Nacional de Salud Pública; 2009

43. Lazcano-Ponce A, Gómez-Dantés O, Rojas R, Garrido-Latorre F. Sistema de Protección Social en Salud. Evaluación externa 2012. Cuernavaca: INSP; 2013.

44. Comisión Nacional de Protección Social en Salud. Libro Blanco. Sistema de Protección Social en Salud. "Seguro Popular". México: Secretaría de Salud. 2012, available online: http://seguropopular.guanajuato.gob.mx/archivos/ transparencia/libros_blancos/seguropopular.pdf.

45. Rwashana AS, Williams DW, Neema S. System dynamics approach to immunization healthcare issues in developing countries: a case study of Uganda. Health Informatics Journal, June 2009.15:2, 95-107. doi:10.1177/ 1460458209102971.

46. Cámara de Diputados de la H Congreso de la Union. Reglamento de la Ley General de Salud en Materia de Protección Social en Salud. Última reforma publicada DOF 17-12-2014. México, 2012:18 Available online: http://www. issste.gob.mx/CEAM/normatividad_2/reglamento\%20de\%20la\%20ley\% 20gral\%20de\%20salud.pdf.

47. Nigenda G, Ruiz-Larios JA, Aguilar-Martinez ME, Bejarano-Arias R Regularización laboral de trabajadores de la salud pagados con recursos del Seguro Popular en México. Salud Publica Mex. 2012;54:616-23.

48. OECD. OECD employment outlook. http://dx.doi.org/10.1787/empl-outlook2011-en, P134. 2011

49. Gomez-Dantes O, Wirtz VJ, Reich MR, Terrazas P, Ortiz M. A new entity for the negotiation of public procurement prices for patented medicines in Mexico. Bull World Health Organ. 2012;90:788-92.

50. Frenk J, Gonzalez-Pier E, Gómez-Dantés O, Lezana MA, Knaul FM. Comprehensive reform to improve health system performance in Mexico. Lancet. 2006;368:1524-34.

51. Agyepong I, Adjei S. Public social policy development and implementation: a case study of the Ghana National Health Insurance scheme. Health Policy Plan. 2008:23:150-60.

52. Hughes D, Leethongdee S. Universal coverage in the land of smiles: lessons from Thailand's 30 Baht health reforms. Health Aff (Millwood). 2007;26: 999-1008.

53. Mikkelsen-Lopez I, Wyss K, de Savigny D. An approach to addressing governance from a health system framework perspective. BMC Int Health Hum Rights. 2011;11.

54. Kamuzora P, Gilson L. Factors influencing implementation of the community health fund in Tanzania. Health Policy Plan. 2007;22:95-102.

55. Freeman III C, Lu-Boyton X, editors. Implementing health care reform policies in China. Challenges and opportunities. USA: Centre for Strategic \& International Studies; 2011.
56. Gorbaneff $Y$, Uribe EM, Torres S, Contreras N. La incertidumbre del entorno en que trabaja la cadena de prestación de servicios de salud. Gerencia y Políticas de Salud 2006;5(11):96-110.

57. Hu S, Tang S, Liu Y, Zhao Y, Escobar ML, de Ferranti D, et al. Reform of how health care is paid for in China: challenges and opportunities (vol 372, pg 1846, 2008). Lancet. 2009;374:292.

\section{Submit your next manuscript to BioMed Central and we will help you at every step:}

- We accept pre-submission inquiries

- Our selector tool helps you to find the most relevant journal

- We provide round the clock customer support

- Convenient online submission

- Thorough peer review

- Inclusion in PubMed and all major indexing services

- Maximum visibility for your research

Submit your manuscript at www.biomedcentral.com/submit
) Biomed Central 